\title{
Evaluating the Applicability of Heritage Flight Hardware in Orion Environmental Control and Life Support Systems
}

\author{
Cynthia D. Cross ${ }^{1}$, John F. Lewis ${ }^{2}$, and Richard A. Barido ${ }^{3}$ \\ NASA Johnson Space Center, Houston, Texas, 77058 \\ Robyn Carrasquillo ${ }^{4}$ \\ NASA Marshal Space Flight Center, Huntsville, Alabama, 35812 \\ and \\ George E. Rains ${ }^{5}$ \\ Jacobs Engineering, Houston, Texas, 77058
}

\begin{abstract}
Recent changes in the overall NASA vision has resulted in further cost and schedule challenges for the Orion program. As a result, additional scrutiny has been focused on the use of new developments for hardware in the environmental control and life support systems. This paper will examine the Orion architecture as it is envisioned to support missions to the International Space Station and future exploration missions and determine what if any functions can be satisfied through the use of existing, heritage hardware designs. An initial evaluation of each component is included and where a heritage component was deemed likely further details are examined. Key technical parameters, mass, volume and vibration loads are a few of the specific items that are evaluated. Where heritage hardware has been identified that may be substituted in the Orion architecture a discussion of key requirement changes that may need to be made as well as recommendation to further evaluate applicability are noted.
\end{abstract}

${ }^{1}$ Orion ECLS Deputy System Manager, EC6/Crew and Thermal Systems Divison

${ }^{2}$ Orion ECLS System Manager, EC6/Crew and Thermal Systems Divison

${ }^{3}$ Orion ECLS ARS Subsystem Manager, EC6/Crew and Thermal Systems Divison

${ }^{4}$ Orion Crew and Thermal FAM, Systems Development, Integration, and Test, ES62. AIAA Member

${ }^{5}$ Orion ECLS PCS Subsystem Manager, EC6/Crew and Thermal Systems Divison. 